\title{
Asymmetric Persuasive Effects of Gain- and Loss-related Messages in Electronic Word of Mouth
}

\author{
Heejae $\operatorname{Shin}^{1} \&$ Wirawan D. Dahana ${ }^{1}$ \\ ${ }^{1}$ Gradute School of Economics, Osaka University, Japan \\ Correspondence: Wirawan D. Dahana, Graduate School of Economics, Osaka University, Toyonaka, Osaka, \\ Japan. Tel: 81-6-6850-5241. E-mail: dony@econ.osaka-u.ac.jp
}

Received: September 28, 2017

Accepted: October 26, 2017

Online Published: November 20, 2017

doi:10.5539/ijbm.v12n12p82

URL: https://doi.org/10.5539/ijbm.v12n12p82

\begin{abstract}
This study examines the aggregate effect of electronic word mouth (eWOM) communications containing multiple messages of different type on brand attitude. It focuses on the moderating role of individuals' regulatory focus and message proportion in influencing the extent to which consumers respond to gain- and loss-related messages. We develop some hypotheses regarding the interplay between the constructs, and test them through two web-based experimental studies on online product reviews. In study 1, we examine the persuasiveness of four different reviews composed of several combinations of gain- and loss-related messages. In study 2, we modify the proportion of positive and negative messages to examine how the impact of eWOM is affected by disproportionate message structure. The results reveal that different combinations of message types lead to different evaluation of the focal brand. Furthermore, subjects with different regulatory focus exhibit different attitudes toward the focal brand when exposed to the same message combination. In addition, the moderating effects of regulatory focus appear to be altered by eWOM message proportion. Theoretical and managerial implications of this study are discussed.
\end{abstract}

Keywords: electronic word of mouth, brand attitude, message valence, regulatory focus

\section{Introduction}

The persuasive impact of eWOM on various aspects of consumer behavior has been well recognized in the literature. Studies have shown that eWOM can affect consumers' attitude toward a brand (Lee, Park, \& Han, 2008; Lee, Rodgers, \& Kim, 2009; Wu \& Wang, 2011), product evaluation (Zhang, Craciun, \& Shin, 2010; Kim \& Gupta, 2012; Dou et al., 2012), purchase intention (Wang, Yu, \& Wei, 2012; Jimenez \& Mendoza, 2013; Fang \& Yu, 2017), and brand choice (Senecal \& Nantel, 2004; Cheung, Lee, \& Rabjohn, 2008; East, Hammond, \& Lomax, 2008). Recent research has indicated the growing number of consumers who perceive eWOM as more reliable than firm-generated communication tools such as prints ads, personal selling, or TV commercials (Trusov, Bucklin, \& Pauwels, 2009; Lee \& Youn, 2009). The primary distinction between eWOM and traditional marketing communications is that the former may contain positive as well as negative messages about a product or service (Hennig-Thurau et al., 2004). Thus, while firm-generated communications are expected to influence consumers in favorable ways, eWOM can cause unfavorable impacts on consumers' attitudes or decisions. Accordingly, how individuals will be ultimately affected by each message that constitutes an eWOM has been a primary concern among academicians and practitioners (King, Racherla, \& Bush, 2014).

However, despite a large body of research on this topic, there is an ongoing conflict about the intensity of eWOM messages. On one hand, a research stream contends that positive messages are more influential than negative messages, a phenomenon well-known as the positivity bias (East et al., 2008; Fang \& Yu, 2017). On the other hand, other researchers assert the negativity bias, that is, the impact of negative messages is greater than positive messages (Skowronski \& Carlston, 1989; Park \& Lee, 2009). With this regard, there is ample work intended to reconcile the conflicting ideas and figure out potential conditions under which positivity or negativity biases are likely to occur. Recent studies have revealed that factors such as product characteristics (Park \& Lee, 2009; Pan \& Zhang, 2011), recipient characteristics (Sen \& Lerman, 2007; Jones, Aiken, \& Boush, 2009), provider characteristics (Shin, Song, \& Biswas, 2013; Hornik et al., 2015), and message characteristics (Park \& Kim, 2008; Melián-González et al., 2013) are likely to moderate the extent to which consumers evaluate and accept a particular message. Focusing on recipient characteristics, few researchers have recently found that 
regulatory focus theory (Higgins, 1997) can be used to better explain under what condition positive messages overwhelm negative messages, and vice versa. Drawing on the theory, positivity (negativity) bias is postulated to occur when promotion (prevention) focus consumer is exposed to positive (negative) messages.

The explanation based on regulatory focus theory seems to be plausible, given the ample evidence that individuals' goal orientations are associated with their attentions and responses to a particular persuasion (Aaker \& Lee, 2001; Lee \& Aaker, 2004; Keller, 2006; Wang \& Lee, 2006). Specifically, when the valence of a message is congruent with consumers' regulatory foci, its effect would appear to be more salient because consumers are more inclined to pay attention and behave in a determined way recommended by the message. However, we argue that the existing literature grounded on the theory have some limitations in the assessment of eWOM effects. First, most studies have focused on a single message that is either positive or negative. This is impractical because in general consumers encounter with eWOM constituted by both positive and negative messages. Therefore, the ultimate effect of eWOM on any outcome variable must be assessed as the net effect of all messages contained. Few studies including Doh and Hwang (2009) and Melián-González et al. (2013) indeed examined the aggregate effects of multiple messages but they did not consider consumers' regulatory focus. Second, existing studies did not account for the fact that for a given message valence, its congruency with consumers' regulatory foci would depend on the type of the message. For example, a positive message can either be the one that conveys the presence of product advantages (gain) or the absence of product disadvantages (non-loss). The impacts of gain and non-loss messages should be different for promotion and prevention focus consumers (Idson, Liberman, \& Higgins, 2000, Liberman, Idson, \& Higgins, 2005). This is also the case for any negative message that can be either the one telling the presence of product disadvantages (loss) or the absence of product advantages (non-gain).

These gaps in the literature remain some open questions: (1) How would consumers' responses to eWOM containing, for example, gain and non-loss messages be different from their responses to that containing gain and loss messages? (2) How can the differences be explained by using regulatory focus theory? (3) How would the outcome change if one of the message types outnumbers the other? In this study, we aimed to address these questions by examining the aggregate effects of online product reviews which are composed of various messages of different types, where brand attitude is considered as the outcome variable. For this purpose, we developed testable relevant hypotheses based on the literature and subsequently conducted two web-based experiments in which we exposed subjects to ten reviews concerning a product in a single board and then asked their attitudes toward the focal product. Individual's regulatory focus was measured by using a scale frequently used in the previous studies. In study 1, we tested the persuasiveness of four different eWOM designed as some combinations of gain-related (gain or non-gain) and loss-related (loss or non-loss) messages. For each eWOM, we balanced the proportion of message valences so that it has five positive and negative messages. In study 2, we extended study 1 by modifying the proportion of positive and negative messages to examine how the results would change when a type of message outnumbers the other.

The main contribution of the present research is that it expands the existing literature on eWOM by taking into account the net effect of several message types: gain, non-gain, loss, and non-loss messages. In that sense, the focus is beyond on positivity and negativity nature of a message as in past studies since it includes the examination of message intensity in terms of individual's goal orientation. The analysis of two studies resulted in some important insights. First, we found that different combinations of message types lead to different responses to eWOM. Second, subjects' responses to eWOM are moderated buy their goal orientations. Third, the moderating effect of regulatory focus appears to be altered by message proportion.

The remainders of this paper are organized as follows. In the next section we discuss the theoretical backgrounds underpinning our expectation the role of one's goal orientation in influencing message intensity. Subsequently, we illustrate the analytical framework used to examine the effect of eWOM. We then describe the experimentation designs and present the results of study 1 and study 2 . Following these sections, we discuss the theoretical and managerial implications of our findings. Finally, we conclude with some limitations and directions for future research.

\section{Theoretical Background}

\subsection{Positivity and Negativity Biases}

Research studies have shown the asymmetric effects of positive and negative messages. However, the results are inconclusive because some researchers found positive messages are stronger than negative messages (i.e., the positivity bias), whereas some others found the other way around (i.e., the negativity bias). For example, it has been shown that people tend to utilize positive WOM, rather than negative WOM, as a main source in the 
adoption of new product (Keaveney, 1995). Further, East et al. (2008) pointed out that because, in many cases, positive messages outnumber negative messages, the impact of the former appears to be greater than the latter. In the context of eWOM, a recent study by Fang and Yu (2017) suggested that positive messages have a greater effect on purchase intention compared to its negative counterparts. By contrast, an early study on traditional WOM by Arndt (1967) revealed that negative messages have greater effect on consumer decision to buy a new product. In the context of product evaluation, Skowronski and Carlston (1989) suggested that consumers put more weight to negative rather than positive information in forming their judgments. More recently, Liao et al. (2015) provided evidence that negative eWOM has a stronger effect in generating information richness than positive eWOM. Other studies supporting negativity bias include Homer and Yoon (1992), Park and Lee (2009) and Richins (1983).

\subsection{Regulatory Focus Theory}

Regulatory Focus theory (Higgins, 1997) suggests two motivational orientations that influence individual's behavioral intention or decision making: promotion and prevention focus. According to the theory, promotionand prevention-focused individuals are influenced by different strategic means; that is, the former tend to employ an approach strategy and the latter tend to employ an avoidance strategy. Specifically, promotion focused individuals would pay more attention to the presence or the absence of gain (an approach strategy), whereas prevention focused consumers are more concerned with the absence or presence of loss (an avoidance strategy) (Aaker \& Lee, 2001; Higgins, 1997; Tuan Pham \& Chang, 2010). Therefore, promotion focused consumers are likely to be sensitive to positive outcomes, whereas prevention focused consumers are likely to be sensitive to negative outcomes.

With regard to individual's response to particular information, the theory implies that the fluency of processing and the likelihood of acceptance of the information should depend on the congruency between its content and the goal of her/his own (Higgins, 2000). That is, information concerning gain (loss) is more likely to be processed and perceived to be more persuasive by promotion- (prevention-) focused individuals. A study by Aaker and Lee (2001) suggested that individuals demonstrate greater recall and more favorable attitude toward information that is compatible with regulatory focus, providing a support for this contention. In the context of eWOM, Kim and Lee (2015) found that promotion-focused subjects rated the usefulness of a positive product review higher than did prevention-focused subjects. The result was reversed when subjects were exposed to a negative product review. Similarly, Zhang, Craciun, and Shin (2010) pointed out that consumers with promotion (prevention) goals tend to perceive positive (negative) reviews to be more persuasive than negative (positive) ones when making product evaluation. In another study, however, the moderating effect of individual regulatory focus was insignificant when message credibility was treated as the outcome variable (Lee and Koo 2012). This is in contradiction with the work by Lee and Yi (2010) who partially found significant moderating effect of regulatory focus on the credibility of negative product reviews, although they did not find the same result for positive reviews.

\subsection{Message Intensity}

Based on regulatory focus and message valence, we can categorize eWOM messages into four types: gain, non-loss, non-gain, and loss (see Table 1). The first two are positive messages presenting the presence (absence) of product advantages (disadvantages) and the last two are negative messages presenting the absence (presence) of product advantages (disadvantages). While most studies on eWOM have focused on the persuasiveness of messages of different valence, it can be expected that for the same valence, the outcomes would vary depending on whether they are gain-related or loss-related messages. In fact, Lee and Aaker (2004) confirmed that gain-framed (i.e., gain and non-gain) messages appeared to be more persuasive when presented to promotion focused subjects than prevention focused subjects, and vice versa. Further, drawing on the principle of loss aversion (Kahneman \& Tversky, 1979), Liberman, et al. (2005) predicted that losses would be perceived as more intensely negative than non-gains, and that non-losses would be perceived as more positive than gains. Their results revealed that this is the case for the former relation, but not for the latter relation. This finding suggests that loss (gain) messages would have greater negative (positive) effect than non-gain (non-loss) messages. However, as the study did not account for individuals' goal orientation, how the results would be different for promotion and prevention focused individuals remains unexplored. 
Table 1. Message Categorization by Valence and Regulatory Focus

\begin{tabular}{ccc}
\hline \multirow{2}{*}{ Message valence } & \multicolumn{3}{c}{ Regulatory focus } \\
\cline { 2 - 4 } & Promotion focus & Prevention focus \\
\hline Positive & Gain & Non-loss \\
Negative & Non-gain & Loss \\
\hline
\end{tabular}

\section{Analytical Framework and Hypotheses}

\subsection{Analytical Framework}

We show the analytical framework of this study in Figure 1. As previously outlined, we aim to examine the aggregate effect of eWOM containing multiple messages of different type on brand attitude. In particular, we consider consumers' responses to online product reviews sent by individuals who have usage experiences of the focal product. There are four message type combinations to examine, each of which contains both positive and negative messages. Note that we exclude the combination containing only negative (loss + non-gain) and positive (gain + non-loss) reviews because besides unrealistic, such one-sided contents may give rise to a severe problem of credibility pertaining to the message (Doh \& Hwang, 2009).

The basic premise of this study is that product reviews containing different message combinations would result in different level of attitude toward a brand. For example, we expect consumers' responses to a combination of gain and non-gain messages would be different from the responses to a combination of gain and loss messages. In so doing, this study measures the aggregate effect of eWOM rather than the effect of individual message. Further, we expect the intensity of each message combination varies across consumers depending on their regulatory focus. That is, brand attitudes resulted from a message combination should be different for promotionand prevention-focused consumers. Moreover, we also account for the moderating role of message ratio to examine how the results would be altered if either message valence outnumbers the other. We examine the interplay between message combinations and regulatory focus in study 1 and the moderating role of message ratio in study 2 .

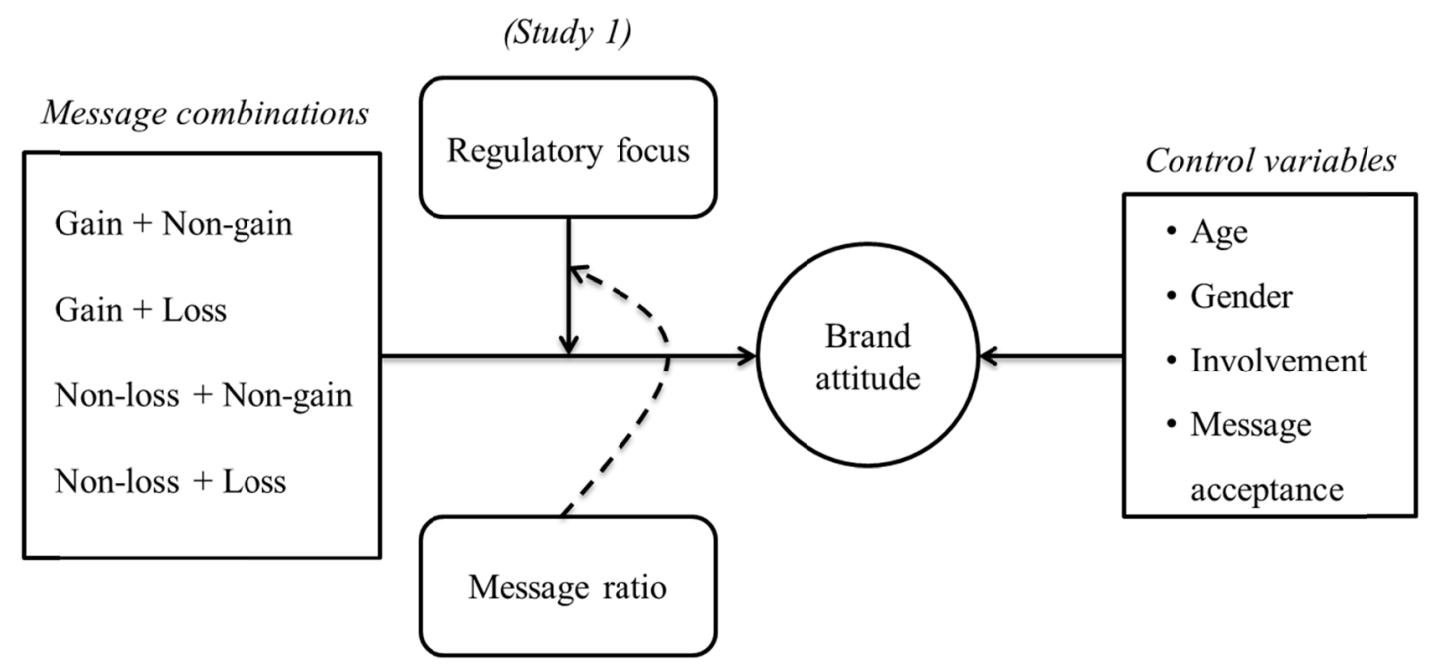

(Study 2)

Figure 1. Analytical framework

Additionally, we control for age, gender, involvement, and message acceptance in our analysis. Recent studies on e-commerce suggested that younger consumers shop online more frequently than do older consumers (Shim \& Drake, 1990 ), indicating that perceived risks toward online shopping are high among elderly (Liebermann \& Stashevsky, 2002). Given that online product reviews can reduce the risks associated with online buying, older consumers should be more responsive to the messages. This stream of research also pointed out that men use the Internet more frequently and for a longer time than women (Garbarino \& Strahilevitz, 2004; Sheehan, 1999), implying that women perceived higher risks on online stores than men (Shim \& Drake, 1990). Accordingly, eWOM should be more influential for women than men. Further, Higgins (2000) argued that the influence of 
regulatory focus would be more salient for low-involvement individuals because they lack ability to make objective evaluation about the encountered information. Thus, the magnitude of its moderating effect should depend on the extent of involvement. Finally, the literature has shown that message acceptance determines the extent to which individuals process a message and behave in accordance with its content (Xu et al., 2010; Iyengar et al., 2015; Gupta \& Harris, 2010). In our context, this implies that the persuasiveness of product reviews would be larger for individuals who are more inclined to accept the messages.

\subsection{Hypotheses}

As suggested by regulatory focus theory, individuals attach different weights to gains and losses according their goal orientations (Halamish et al., 2008; Zhang et al., 2010). This implies that the persuasive effect of a message depends on whether it conveys gain-related or loss-related information (Higgins, 2000). Promotion (prevention) focused individuals will pay more attention to and are more likely to be influenced by gain-related (loss-related) messages. Thus, the impacts would be enhanced when there is congruency between message type and regulatory focus. For example, the fit between information type and individuals' goal orientation should result in better recall and attitude toward the content of the information (Aaker \& Lee, 2001). This argument should also apply in the context of eWOM, where consumers perceive its messages as more persuasive if the valence of the messages is congruent with their regulatory focus. Hence,

\section{H1: Individual's regulatory focus moderates the impacts of eWOM containing different type of messages on brand attitude.}

Furthermore, as pointed out by Idson et al. (2000) and Liberman et al. (2005), individuals perceive that the pleasure from gains is greater than the pleasure from non-losses. While these studies built the premise for a single message, it is plausible to expect the same to hold for the case when multiple messages are exposed simultaneously. However, the results should vary depending on individual's regulatory focus. For promotion focused consumers, an eWOM containing gain and non-gain messages should result in more favorable attitudes than that containing non-loss and non-gain messages, provided that they attach greater weight to gain-related messages (Lee \& Aaker, 2004). By contrast, for prevention focused consumers, the latter should lead to more favorable attitudes than do the former because they are more influenced by non-loss messages than by gain messages. In other words, the positivity of gain messages is less influential than that of non-loss messages for these consumers. Using the same reasoning, we expect to observe the same results when gain and non-loss messages are combined by loss messages. Hence,

H2: Promotion (prevention) focused consumers will have more (less) favorable brand attitude when receiving gain/non-gain eWOM than they will when receiving non-loss/non-gain eWOM.

H3: Promotion (prevention) focused consumers will have more (less) favorable brand attitude when receiving gain/loss eWOM than they will when receiving non-loss/loss eWOM.

Another important finding from the study by Liberman et al. (2005) is that the pain from losses is greater than the pain from non-gains, which is consistent with the principle of loss aversion (Kahneman \& Tversky, 1979; Tversky, 1994). In line with our previous predictions, we expect the argument to hold when loss and non-gain messages are combined with gain and non-loss messages. Specifically, it can be expected that eWOM containing loss and gain messages should result in unfavorable attitudes compared to those containing non-gain and gain messages for prevention focused consumers, provided that the negativity of loss messages are more salient for these consumers. By contrast, promotion focused consumers are likely to find the former to be less negative than the latter because they are less influenced loss-related messages. Applying the same reasoning to the case when the negative messages are combined with non-loss messages, we expect the same results for (loss + non-loss) and (non-gain + non-loss) combinations. Hence,

H4: Promotion (prevention) focused consumers will have more (less) favorable brand attitude when receiving loss/gain eWOM than they will when receiving non-gain/gain eWOM.

H5: Promotion (prevention) focused consumers will have more (less) favorable brand attitude when receiving loss/non-loss eWOM than they will when receiving non-gain/non-loss eWOM.

Additionally, being composed of both positive and negative messages, eWOM persuasiveness may be affected by the ratio of message valences. Intuitively, if positive messages outnumber negative messages, then the positivity of the eWOM will become more intense, and vice versa. A study by Doh and Hwang (2009) revealed that a higher ratio of positive messages in eWOM results in more favorable attitudes and higher purchase intentions. However, they results also suggested that when all messages contained are positive, the credibility of the eWOM turns to diminish. In the context of this study, message proportions may enhance the role of message 
valence in consumer evaluation about a brand, altering the moderating effect of regulatory focus. For example, an eWOM containing the same number of gain and loss messages should result in favorable (unfavorable) brand attitude for promotion (prevention) focused consumers. However, when positive messages outnumbers negative messages, prevention focused consumers are likely to have favorable brand attitude, as promotion focused consumers do. Hence,

H6: When messages of either valence outnumber the others, the effect of message valence on brand attitude will overwhelm the effect of regulatory focus.

\section{Study 1}

\subsection{Outline}

In study 1, we conducted a web-based experiment to examine the moderating effect of regulatory focus and brand attitude differences as stated in $\mathrm{H} 1$ through $\mathrm{H} 5$. We designed four online reviews concerning a toothpaste product, each of which contains 5 positive and 5 negative statements (see Appendix A), representing message combinations depicted in Figure 1. To measure brand attitude, the dependent variable, we used four items rated in a five-point scale: low/high quality, bad/good, unfavorable/favorable, and negative/positive (Swaminathan et al., 2007). Individual's regulatory focus was measured by a scale used in Lockwood et al. (2002) and Lee and Koo (2012). The scale is composed of eight items representing the extent to which an individual is inclined to pursue gains and avoid losses. The sum of the latter items was subtracted from that of the former items, and then the median of the differences was used to split the subjects into promotion- and prevention-focused consumers. Further, we measured product involvement by asking how the subjects perceive the toothpaste category in a seven-point scale: unimportant/important, unattractive/attractive, and uninteresting/interesting (Zaichkowsky, 1985). In addition, message acceptance was measured by the scale proposed by (Lee \& Koo, 2012; Cheung et al., 2009; Zhang \& Watts, 2008).

\subsection{Sample and Procedure}

The experiment was conducted by an online research company targeted at randomly chosen 200 subjects (100 men). The ages of the subjects range from 15 to 69 years old, and the average was 40.28 years old. Table 2 shows the experimental design of this study. There are four groups receiving 10 product reviews containing different message combinations. We assigned each subject to one of the groups, and thus, all groups have 50 subjects. At the beginning of the experiment, we presented the product reviews in a single board to the subjects and asked them to read the reviews carefully. The order of the reviews shown to each subject was randomized to rule out the primacy and recency effects. After completing this task, we asked the subject evaluate the toothpaste brand to measure their attitudes. Finally, we asked them to answer the questionnaire on involvement, message acceptance, and regulatory focus.

Table 2. Experimental design

\begin{tabular}{ll}
\hline Message combination & Regulatory focus \\
\hline 5 gain +5 non-gain & Promotion-focused \\
5 gain +5 loss & Prevention-focused \\
& Promotion-focused \\
5 non-loss +5 non-gain & Prevention-focused \\
& Promotion-focused \\
5 non-loss +5 loss & Prevention-focused \\
& Promotion-focused \\
\hline
\end{tabular}

\subsection{Manipulation Check}

To assure that the gain- and loss-related messages are perceived as different message types, we conducted a manipulation check targeted at 30 undergraduate and graduate students (13 males). First, we showed them the product reviews containing 5 gain, 5 non-gain, 5 loss, and 5 non-loss messages, and then asked them whether each message was telling the presence (or absence) of the advantages (or disadvantages) of the product. 
Subsequently, we conducted a chi-squared test to examine whether the answers were close enough to the assumed values. The result of the chi-squared test suggested that there is no significant differences between the answers and the assumed values $\left(\chi^{2}(3)=2.17, \mathrm{p}>0.10\right)$.

\subsection{Reliability and Validity Assessment}

We tested the reliability and validity of the constructs (attitude, promotion focus, prevention focus, involvement, and message acceptance) by conducting an exploratory factor analysis and confirmed that all items converged to the intended factors. Internal consistency reliability was evaluated by using the Cronbach alpha and item-to-total correlations (see Table 3). The values of the Cronbach alpha ranged from 0.82 to 01.89 , and the values of item-total correlations ranged from 0.65 to 0.82 , which were greater than the recommendled value (Kline, 2000). The convergent validity of the measurement items was tested by factor loadings, composite reliability, and the variance-extracted measures. We confirmed that the factor loadings of all items were greater than 0.60. Likewise, all the composite reliabilities were greater than 0.80 , and all variance-extracted measure were greater than 0.50 , suggesting the convergence of the measurement items (Kline, 2000). Finally, we compared the error-adjusted inter-construct correlations with their respective variance extracted measures to test the discriminant validity (Fornell \& Larcker, 1981). The results revealed that all correlations were less than the variance extracted measures of the respective constructs; thus, we confirmed discriminant validity among the constructs.

Table 3. Internal Reliability and Convergent Validity

\begin{tabular}{|c|c|c|c|c|c|}
\hline \multirow[b]{2}{*}{ Item } & \multicolumn{2}{|c|}{ Internal reliability } & \multicolumn{3}{|c|}{ Convergent validity } \\
\hline & Cronbach $\alpha$ & $\begin{array}{l}\text { Item-total } \\
\text { correlation }\end{array}$ & Loading & $\begin{array}{l}\text { Composite } \\
\text { reliability }\end{array}$ & $\begin{array}{l}\text { Variance } \\
\text { extracted }\end{array}$ \\
\hline Brand attitude & 0.93 & & & 0.93 & 0.76 \\
\hline $\mathrm{Bad} /$ Good & & 0.84 & 0.80 & & \\
\hline Unfavorable / Favorable & & 0.80 & 0.92 & & \\
\hline Negative / Positive & & 0.86 & 0.88 & & \\
\hline In general, I am focused on achieving positive outcomes in my life. & & 0.81 & 0.83 & & \\
\hline I often imagine myself experiencing good things that I hope will happen to me. & & 0.75 & 0.72 & & \\
\hline Overall, I am more oriented toward achieving success than preventing failure. & & 0.72 & 0.78 & & \\
\hline Prevention focus & 0.80 & & & 0.81 & 0.72 \\
\hline I frequently think about how I can prevent failure in my life. & & 0.83 & 0.88 & & \\
\hline In general, I am focused on preventing negative events in my life. & & 0.79 & 0.71 & & \\
\hline Appealing / Unappealing & & 0.79 & 0.84 & & \\
\hline Uninterested / Interested & & 0.81 & 0.90 & & \\
\hline Message acceptance & 0.85 & & & 0.87 & 0.77 \\
\hline Consumer reviews are helpful to me when deciding on brands to buy. & & 0.78 & 0.88 & & \\
\hline Consumer reviews can motivate me to purchase products. & & 0.81 & 0.88 & & \\
\hline
\end{tabular}

\subsection{Results and Discussion}

To examine the moderating role of regulatory focus, we conducted a 4 (message combination) $\times 2$ (regulatory focus) analysis of covariance (ANCOVA) by treating gender, age, involvement, and message acceptance as control variables. The result is shown in Table 4. As can be seen, the interaction effect between message combination and regulatory focus is significant $(\mathrm{F}(3,188)=3.24, \mathrm{p}=0.02)$, providing a support for H1. Thus, given a fixed message combination, we confirmed that individual's response to the product review is partly determined by her/his goal orientation. However, we note that regulatory focus alone does not describe brand attitude differences, provided that its main effect was insignificant $(\mathrm{F}(1,188)=0.48, \mathrm{p}>0.10)$. Further, we also found that the main effect of message combination was significant $(\mathrm{F}(1,188)=2.81, \mathrm{p}=0.04)$, indicating that different message combination would result in different brand attitude for average consumers. Additionally, product involvement appeared to have significant effect on brand attitude, suggesting that the failure to account for its effect would result in biases in the estimates of the key variables. For other control variables, we observed that the effects were insignificant. 
Table 4. The Result of ANCOVA

\begin{tabular}{|c|c|c|}
\hline Variable & F value & $\operatorname{Pr}(>\mathrm{F})$ \\
\hline Message combination (MC) & 2.81 & 0.04 \\
\hline Regulatory focus (RF) & 0.48 & 0.49 \\
\hline $\mathrm{MC} \times \mathrm{RF}$ & 3.24 & 0.02 \\
\hline Gender & 0.03 & 0.87 \\
\hline Age & 0.03 & 0.89 \\
\hline Involvement & 3.92 & 0.05 \\
\hline Message acceptance & 0.40 & 0.53 \\
\hline
\end{tabular}

Bold indicates significant effect at $\alpha=0.05$.

Figure 2 shows the average brand attitude for all experimental groups. First, we compared the values with respect to Gain/Non-gain and Non-loss/Non-gain groups. For promotion-focused consumers, the difference of mean attitudes between the two groups was significant $(\mathrm{t}(48)=2.01, \mathrm{p}=0.03)$, in support of H2. However, this is not the case for prevention-focused consumers for which the difference was insignificant $(\mathrm{t}(48)=-0.09, \mathrm{p}>$ 0.10). Thus, we concluded that $\mathrm{H} 2$ was supported only for promotion-focused consumers. Next, we tested the difference between Gain/Loss and Non-loss/Loss groups. The result indicated that the difference was significant for promotion-focused consumers $(\mathrm{t}(48)=1.97, \mathrm{p}=0.03)$. Likewise, we observed that the difference was also significant with the expected sign for prevention-focused consumers $(t(48)=-3.21, p<0.01)$, provided a support for H3. Our analysis revealed that, for promotion-focused consumers, the positivity intensity of gain messages are greater than that of non-loss messages, which is true even when the messages are combined with other messages of different type. By contrast, the positivity of gain messages appeared to be less influential for prevention-focused consumers, perhaps because they were more interested in loss-related messages than gain-related messages.

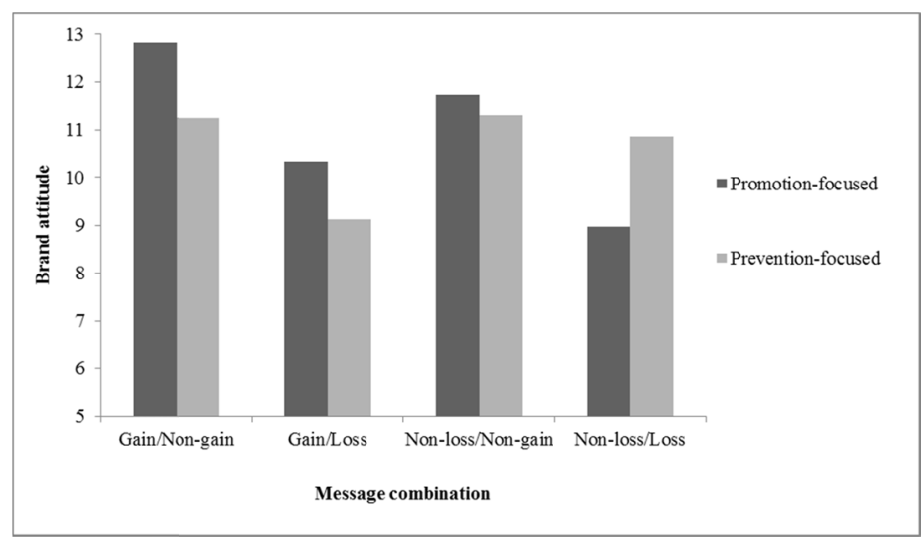

Figure 2. Average Brand Attitude of Each Experimental Group

Next, we compared the difference between Gain/Loss and Gain/Non-gain groups. The result for promotion-focused consumers was significant $(\mathrm{t}(48)=-2.26, \mathrm{p}=0.01)$; however, the average of the former was smaller than that of the latter, which is in contradiction with our prediction, leading to the rejection of $\mathrm{H} 4$. By contrast, the result for prevention-focused consumers was moderately significant and with the expected direction $(\mathrm{t}(48)=-1.96, \mathrm{p}=0.03)$. Accordingly, H4 was supported for these consumers. Finally, we tested the difference between Non-loss/Loss and Non-loss/Non-gain groups. For promotion-focused consumers, although significant, the average value of the former group appeared to be smaller than that of the latter group, resulting in the rejection of $\mathrm{H} 5$ for the consumers. The result for prevention-focused consumers was insignificant $(\mathrm{t}(48)=-0.35$, $p=0.36$ ), which again resulted in the rejection of H5. These results suggest that the negativity of loss messages are perceived to be intense not only by prevention-focused but also by promotion-focused consumers. Thus, while prior studies pointed out that promotion-focused consumers pay less attention to loss-related messages (e.g., Aaker \& Lee 2001; Lee \& Aaker 2004), our analysis shows that this might not be the case in a situation when multiple messages of different types are simultaneously exposed to consumers. 


\section{Study 2}

\subsection{Outline}

In study 2, we modified the proportion of message valences shown in a single board so that either positive or negative messages outnumber the others. In particular, we designed some message combinations containing 7 positive (negative) messages and 3 negative (positive) messages. This resulted in eight experimental groups which were exposed to different message type and proportion (see Table 5). We expected positivity (negativity) biases become more salient when positive (negative) messages were dominant in the product reviews, diminishing the moderating roles of regulatory focus.

Table 5. Experimental design of study 2

\begin{tabular}{cll}
\hline \multirow{2}{*}{ Group no. } & \multicolumn{1}{c}{ Message valence } \\
\cline { 2 - 4 } & \multicolumn{1}{c}{ Positive messages } & \multicolumn{1}{c}{ Negative messages } \\
\hline 1 & 7 gain & 3 loss \\
3 & 7 gain & 3 non-gain \\
4 & 7 non-loss & 3 loss \\
5 & 7 non-loss & 7 non-gain \\
6 & 3 gain & 7 loss \\
7 & 3 gain & 7 non-gain \\
8 & 3 non-loss & 7 loss \\
\hline
\end{tabular}

\subsection{Sample and Procedure}

As in study 1, we conducted a web-based experiment to a randomly chosen 400 sample (200 men). Each subject was assigned to one of the eight experimental groups such that each group was composed of 50 subjects. The procedure was completely identical to that used in study 1 . That is, we presented the product reviews to the subjects and then asked their attitude toward the brand under consideration along with involvement and message acceptance variables. However, to enhance external validity, in study 2 we selected a brand from body soap category as the experimental object rather than toothpaste category used in study 1.

\subsection{Manipulation Check}

To assure that the reviews containing 7 positive (negative) messages are perceived as positive (negative) reviews, we conducted a manipulation check targeted at 56 undergraduate students enrolling a marketing course in a large state university in Western Japan. The participant were exposed to one of the eight message combinations and then asked to evaluate the reviews whether it sounded positive or negative in aggregate in a 5-point Likert scale ( $1=$ negative, $5=$ =positive). We subsequently conducted pairwise comparisons between two combinations of the same message type but with different proportion, and confirmed that positive dominant reviews are perceived as more positive than negative dominant reviews, and vice versa. For example, the test between the first group (7 gain : 3 non-gain) and the fifth group (3 gain : 7 non-gain) resulted in the rejection of the null hypothesis that there is no difference between the two $(\mathrm{t}(54)=4.82, \mathrm{p}<0.01)$.

\subsection{Result and Discussion}

We applied ANCOVA to subsamples with different message ratio to examine the influence of disproportionate message structure. Table 6 shows the results of the test. First, when positive messages outnumber negative messages, the interaction effect between message combination and regulatory focus turned to be insignificant $(\mathrm{F}(3,188)=0.62, \mathrm{p}=0.60)$, indicating that the moderating role of regulatory focus was weakened for product reviews dominated by positive messages. Further, when negative messages accounted for a larger portion in the product reviews, the interaction effect was significant $(F(3,188)=2.97, \mathrm{p}=0.03)$; however, the magnitude of the F-value was smaller than that when positive and negative messages are of the same ratio as in study 1 (2.97 vs. 3.24). Because the F-value can be interpreted as the degree of deviance from the null hypothesis, we concluded that the moderating effect of regulatory focus is also weakened when negative messages outnumber positive messages. 
Table 6. The Result of ANCOVA

\begin{tabular}{lcccccc}
\hline \multirow{2}{*}{ Variable } & \multicolumn{2}{c}{ Positive $>$ Negative } & & \multicolumn{2}{c}{ Negative $>$ Positive } \\
\cline { 2 - 3 } \cline { 5 - 6 } & F value & $\operatorname{Pr}(>\mathrm{F})$ & & F value & $\operatorname{Pr}(>\mathrm{F})$ \\
\hline Message combination $(\mathrm{MC})$ & $\mathbf{3 . 1 4}$ & $\mathbf{0 . 0 3}$ & & $\mathbf{7 . 4 2}$ & $\mathbf{0 . 0 0}$ \\
Regulatory focus (RF) & 0.39 & 0.53 & & 0.28 & 0.59 \\
$\mathrm{MC} \times \mathrm{RF}$ & 0.62 & 0.60 & & $\mathbf{2 . 9 7}$ & $\mathbf{0 . 0 3}$ \\
Gender & 0.05 & 0.82 & & 0.09 & 0.76 \\
Age & 0.04 & 0.84 & & 0.01 & 0.92 \\
Involvement & 2.17 & 0.14 & & 3.14 & 0.07 \\
Message acceptance & 0.43 & 0.51 & & 0.36 & 0.54 \\
\hline
\end{tabular}

Bold indicates significant effect at $\alpha=0.05$.
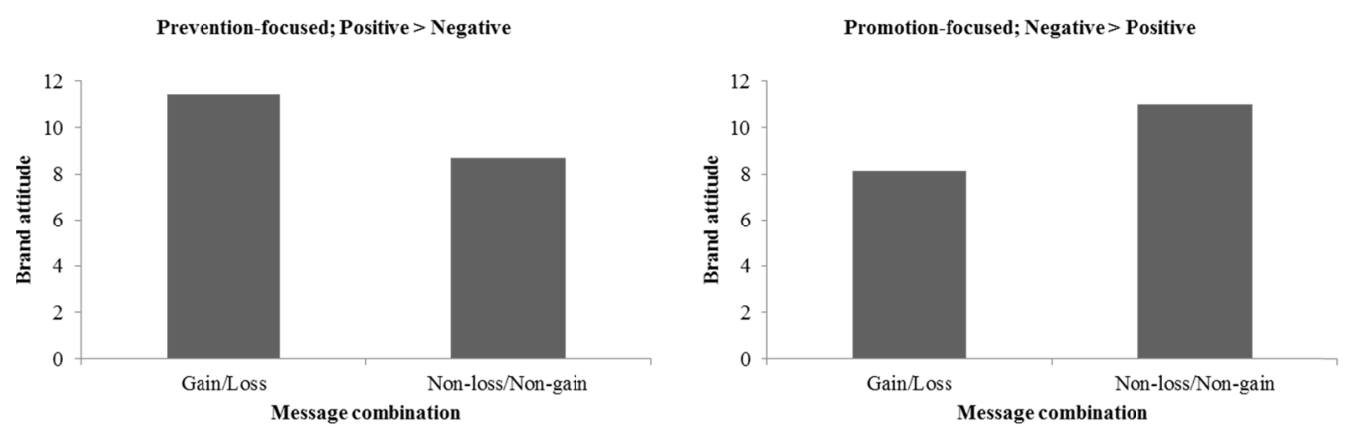

Figure 3. Average Brand Attitude for Different Message Ratio

We further investigated the effect of message ratio by comparing group-level brand attitude for gain/loss and non-loss/gain combinations (see Figure 3). The idea is that if message ratio reduces the moderating effect of regulatory focus, then prevention-focused consumers should have favorable attitude toward a brand when positive messages outnumber negative messages, owing to the intense positivity of gain or non-loss messages. Likewise, promotion-focused consumers should have unfavorable attitude toward a brand when negative messages outnumber positive messages, provided the increasing negativity of loss or non-gain messages. When this is the case, individual's regulatory focus becomes less important, and attitude formation is largely governed by the valence of the messages. Recall that we measured brand attitude as the sum of four items in a five-point scale. Thus, the attitude of a subject is said to be unfavorable if it takes a value less than $8(2 \times 4$ items $)$. Accordingly, we can verify the argument by conducting a test whether the attitude of prevention-focused (promotion-focused) consumers is greater (less) than 8 when positive (negative) messages outnumber negative (positive) messages.

The result of the former for Gain/Loss combination revealed that the attitude of prevention-focused consumers was significantly greater than $8(\mathrm{t}(48)=2.20, \mathrm{p}=0.02)$. By contrast, the result was insignificant for Non-loss/Non-gain combination $(\mathrm{t}(48)=0.28, \mathrm{p}=0.39)$. The results imply that the evaluation made by prevention-focused consumers turns to be favorable only when gain messages outnumber loss messages, but not when non-loss messages outnumber non-gain messages. We conjecture that this might be because the positivity of non-loss messages is weak, resulting in insignificant increase in brand attitude even when they dominate non-gain messages. For the case in which negative messages outnumber positive messages, the test revealed that the null hypothesis cannot be rejected $(\mathrm{t}(48)=0.08, \mathrm{p}=0.47)$, indicating that promotion-focused consumers tend to have unfavorable attitude toward the brand when loss messages outnumber gain messages. However, for Non-loss/Non-gain combination, brand attitude of the consumers was significantly greater than $8(\mathrm{t}(48)=1.99, \mathrm{p}$ $=0.03$ ), suggesting that higher proportion of non-gain messages did not lead to unfavorable attitudes. In sum, the results show that disproportionate message structure can increase the effect message valence and decrease the effect of regulatory focus, particularly for Gain/Loss combination, providing partial support for H6.

\section{Implications}

\subsection{Theoretical Implications}

Research studies on the intensity of positive and negative information have resulted in a contention about which 
message valence is more influential. The consensus on this issue has not been reached because both conflicting ideas have empirical supports from the literature. The application of regulatory focus theory provides an alternative explanation concerning certain conditions under which positivity and negativity biases tend to occur (Kim \& Lee, 2015; Zhang et al., 2010). This study extended previous findings by examining multiple messages of different type contained in a product review simultaneously. Consistent with previous findings, we confirmed that consumers' responses to eWOM vary depending on their goal orientations. Further, our results suggested that positivity bias is likely to occur when promotion-focused consumers receive eWOM containing gain messages. Likewise, negativity bias is likely to occur when prevention-focused consumers are exposed to eWOM containing loss messages. However, the extent of the biases appeared to be lower when promotion-focused consumers receive non-loss messages or when prevention-focused consumers receive non-gain messages. Our study also revealed that the moderating role of regulatory focus can be altered when eWOM contains disproportionate message valences. Specifically, when eWOM is dominated by gain messages, positivity bias can occur for prevention-focused consumers. Similarly, when loss messages are dominant, negativity bias may occur among promotion-focused recipients. Thus, our research contributes to the literature by elucidating how the interplay among message type, regulatory focus, and message ratio can give rise to positivity and negativity biases.

\subsection{Managerial Implications}

In addition, our findings may also be useful for marketers to anticipate the sales impacts of eWOM. Specifically, we argue that the understanding of how various message types would affect brand attitudes should be helpful for firms to better predict future sales by including product reviews as one of the predictors. For example, when the proportion of positive and negative messages is approximately equal, gain messages will result in more favorable brand attitude than non-loss messages, regardless of the type of other messages combined. Thus, marketers may expect an increase in the sales of their products if many consumers tell the others about the advantages of their products. Accordingly, our analysis suggest that marketers should design their marketing communications to improve consumers' understanding of the value of their products so that the consumers will help them spread positive eWOM, particularly gain messages, about the products.

More importantly, marketers should concern with the negative impacts of loss messages, rather than non-gain messages, because they may inflict appalling damage on their brand image, which eventually reduces consumers' purchase intention. Thus, if many consumers send loss messages about a product, this would result in a considerable decrease in the future sales. For this reason, some researchers emphasize the importance of managing negative online reviews to minimize the damage they would make (Lee et al., 2008). Although in many situations it would be difficult to restrict the number of such reviews, larger online providers like Amazon.com has been successful in reducing the number of harmful loss messages by providing guidelines that prohibit "profanity, obscenities, or spiteful remarks" for consumers who are willing to write a review. Further, if a manager is able to decide the order in which the reviews are displayed, she may place gain messages in the first order to be easily visible, and loss messages after the others, as suggested by the primacy effect (Lee \& Koo, 2012).

\section{Conclusion}

This study investigated the aggregate effect of eWOM communication on brand attitude by taking into account the role of message valence, individual's regulatory focus, and message ratio. Through two web-based experimental studies, we examined how consumers' responses varied depending on message combination and regulatory focus, and the results supported the interaction effect between these variables. Further, this study provided evidence that the positivity (negativity) of gain (loss) messages is greater than that of non-loss (non-gain) messages in the context of eWOM. Finally, we confirmed the influence of message ratio in altering the moderating effect of regulatory focus. However, despite the substantial contribution it made to the body of knowledge, we note some limitations of this study. First, we only considered two grocery products whose attributes are relatively easier to evaluate prior to direct inspection. Thus, different results are likely to be derived if the analysis is conducted on experience goods such as automobiles or cosmetics for which the impact of eWOM on consumer decision tends to be greater. Second, we did not examine the potential effect of the order by which the messages are presented to the subjects. As suggested by previous studies, successive opposing messages can influence the final judgment or evaluation of a product (Haugtvedt \& Wegener, 1994; Brunel \& Nelson, 2003). Future research could address these issues by manipulating the message order and examining a wider range of products to improve its generalizability. 


\section{Acknowledgments}

This research was supported by JSPS KAKENHI [grant number A26285095a, 17H02573].

\section{References}

Aaker, J. L., \& Lee, A. Y. (2001). "I" seek pleasures and "we" avoid pains: The role of self-regulatory goals in information processing and persuasion. Journal of Consumer Research, 28(1), 33-49. https://doi.org/10.1086/321946

Arndt, J. (1967). Role of product-related conversations in the diffusion of a new product. Journal of marketing Research, 4(3), 291-295. https://doi.org/10.2307/3149462

Brunel, F. F., \& Nelson, M. R. (2003). Message order effects and gender differences in advertising persuasion. Journal of Advertising Research, 43(3), 330-341. https://doi.org/10.1017/S0021849903030320

Cheung, C. M., Lee, M. K., \& Rabjohn, N. (2008). The impact of electronic word-of-mouth: The adoption of online opinions in online customer communities. Internet Research, 18(3), 229-247. https://doi.org/10.1108/10662240810883290

Doh, S. J., \& Hwang, J. S. (2009). How consumers evaluate eWOM (electronic word-of-mouth) messages. Cyber Psychology \& Behavior, 12(2), 193-197. https://doi.org/10.1089/cpb.2008.0109

Dou, X., Walden, J. A., Lee, S., \& Lee, J. Y. (2012). Does source matter? Examining source effects in online product reviews. Computers in Human Behavior, 28(5), 1555-1563. https://doi.org/10.1016/j.chb.2012.03.015

East, R., Hammond, K., \& Lomax, W. (2008). Measuring the impact of positive and negative word of mouth on brand purchase probability. International Journal of Research in Marketing, 25(3), 215-224. https://doi.org/10.1016/j.ijresmar.2008.04.001

Fang, Wenchang. \& Yu, Chian-Son. (2017). Understand the Influence of Online Word-of-Mouth on Consumer Purchase Intention: The Moderating Effect of Conformity. Journal of Innovation and Management, 13(1), $1-25$.

Fornell, C., \& Larcker D. F. (1981). Evaluating structural equation models with unobservable variables and measurement error. Journal of Marketing Research, 18(1), 39-50. https://doi.org/10.2307/3151312

Garbarino, E., \& Strahilevitz, M. (2004). Gender differences in the perceived risk of buying online and the effects of receiving a site recommendation. Journal of Business Research, 57(7), 768-775. https://doi.org/10.1016/S0148-2963(02)00363-6

Gupta, P., \& Harris, J. (2010). How e-WOM recommendations influence product consideration and quality of choice: A motivation to process information perspective. Journal of Business Research, 63(9), 1041-1049. https://doi.org/10.1016/j.jbusres.2009.01.015

Halamish, V., Liberman, N., Higgins, E. T., \& Idson, L. C. (2008). Regulatory focus effects on discounting over uncertainty for losses vs. gains. Journal of Economic Psychology, 29(5), 654-666. https://doi.org/10.1016/j.joep.2007.09.002

Haugtvedt, C. P., \& Wegener, D. T. (1994). Message order effects in persuasion: An attitude strength perspective. Journal of Consumer Research, 21(1), 205-218. https://doi.org/10.1086/209393

Hennig-Thurau, T., Gwinner, K. P., Walsh, G., \& Gremler, D. D. (2004). Electronic word-of-mouth via consumer-opinion platforms: What motivates consumers to articulate themselves on the Internet? Journal of Interactive Marketing, 18(1), 38-52. https://doi.org/10.1002/dir.10073

Higgins, E. T. (1997). Beyond pleasure and pain. American psychologist, 52(12), 1280-1300. http://psycnet.apa.org/doi/10.1037/0003-066X.52.12.1280

Higgins, E. T. (2000). Making a good decision: value from fit. American psychologist, 55(11), 1217-1230. https://doi.org/10.1037/0003-066X.55.11.1217

Homer, P. M., \& Yoon, S. G. (1992). Message framing and the interrelationships among ad-based feelings, affect, and cognition. Journal of Advertising, 21(1), 19-33. http://dx.doi.org/10.1080/00913367.1992.10673357

Hornik, J., Satchi, R. S., Cesareo, L., \& Pastore, A. (2015). Information dissemination via electronic word-of-mouth: Good news travels fast, bad news travels faster! Computers in Human Behavior, 45, 273-280. https://doi.org/10.1016/j.chb.2014.11.008 
Idson, L. C., Liberman, N., \& Higgins, E. T. (2000). Distinguishing gains from nonlosses and losses from nongains: A regulatory focus perspective on hedonic intensity. Journal of Experimental Social Psychology, 36(3), 252-274. https://doi.org/10.1006/jesp.1999.1402

Iyengar, R., Van den Bulte, C., \& Lee, J. Y. (2015). Social contagion in new product trial and repeat. Marketing Science, 34(3), 408-429. https://doi.org/10.1287/mksc.2014.0888

Jiménez, F. R., \& Mendoza, N. A. (2013). Too popular to ignore: The influence of online reviews on purchase intentions of search and experience products. Journal of Interactive Marketing, 27(3), 226-235. https://doi.org/10.1016/j.intmar.2013.04.004

Jones, S. A., Aiken, K. D., \& Boush, D. M. (2009). Integrating experience, advertising, and electronic word of mouth. Journal of Internet Commerce, 8(3-4), 246-267. http://dx.doi.org/10.1080/15332860903467664

Kahneman, D., \& Tversky, A. (1979). Prospect theory: An analysis of decision under risk. Econometrica: Journal of the econometric society, 47(2), 263-291. https://doi.org/10.2307/1914185

Keaveney, S. M. (1995). Customer switching behavior in service industries: An exploratory study. The Journal of Marketing, 71-82. https://doi.org/10.2307/1252074

Keller, P. A. (2006). Regulatory focus and efficacy of health messages. Journal of Consumer Research, 33(1), 109-114. https://doi.org/10.1086/504141

Kim, J., \& Gupta, P. (2012). Emotional expressions in online user reviews: How they influence consumers' product evaluations. Journal of Business Research, 65(7), 985-992. https://doi.org/10.1016/j.jbusres.2011.04.013

Kim, M., \& Lee, M. (2015). Effects of review characteristics and consumer regulatory focus on perceived review usefulness. Social behavior and personality: an international journal, 43(8), 1319-1333. https://doi.org/10.2224/sbp.2015.43.8.1319

King, R. A., Racherla, P., \& Bush, V. D. (2014). What we know and don't know about online word-of-mouth: A review and synthesis of the literature. Journal of Interactive Marketing, 28(3), 167-183. https://doi.org/10.1016/j.intmar.2014.02.001

Kline, P. (2000). The handbook of psychological testing (2nd ed.). London: Routledge.

Lee, A. Y., \& Aaker, J. L. (2004). Bringing the frame into focus: the influence of regulatory fit on processing fluency and persuasion. Journal of personality and social psychology, 86(2), 205-218. http://psycnet.apa.org/doi/10.1037/0022-3514.86.2.205

Lee, J., Park, D. H., \& Han, I. (2008). The effect of negative online consumer reviews on product attitude: An information processing view. Electronic commerce research and applications, 7(3), 341-352. https://doi.org/10.1016/j.elerap.2007.05.004

Lee, K. T., \& Koo, D. M. (2012). Effects of attribute and valence of e-WOM on message adoption: Moderating roles of subjective knowledge and regulatory focus. Computers in Human Behavior, 28(5), 1974-1984. https://doi.org/10.1016/j.chb.2012.05.018

Lee, K., \& Yi, H. (2010). Effects of the valence of eWOM on perceived message credibility. Journal of Internet electronic commerce research, 10(4), 75-95.

Lee, M., \& Youn, S. (2009). Electronic word of mouth (eWOM) How eWOM platforms influence consumer product judgement. International Journal of Advertising, 28(3), 473-499. http://dx.doi.org/10.2501/S0265048709200709

Lee, M., Rodgers, S., \& Kim, M. (2009). Effects of valence and extremity of eWOM on attitude toward the brand and website. Journal of Current Issues \& Research in Advertising, 31(2), 1-11. http://dx.doi.org/10.1080/10641734.2009.10505262

Liao, S., Lee, C. T. Y., Lin, T. H., \& Lin, M. C. (2015). eWOM richness of leisure farm tour experience: Influences of message valence, product type and consumer knowledge. Journal of Marketing Management, 3(2), 55-68. http://dx.doi.org/10.15640/jmm.v3n2a6

Liberman, N., Idson, L. C., \& Higgins, E. T. (2005). Predicting the intensity of losses vs. non-gains and non-losses vs. gains in judging fairness and value: A test of the loss aversion explanation. Journal of Experimental Social Psychology, 41(5), 527-534. https://doi.org/10.1016/j.jesp.2004.06.007

Liebermann, Y., \& Stashevsky, S. (2002). Perceived risks as barriers to Internet and e-commerce usage. 
Qualitative Market Research: An International Journal, 5(4), 291-300. https://doi.org/10.1108/13522750210443245

Lockwood, P., Jordan, C. H., \& Kunda, Z. (2002). Motivation by positive or negative role models: Regulatory focus determines who will best inspire us. Journal of Personality and Social Psychology, 83(4), 854-864. https://doi.org/10.1037//0022-3514.83.4.854

Melián-González, S., Bulchand-Gidumal, J., \& González López-Valcárcel, B. (2013). Online customer reviews of hotels: As participation increases, better evaluation is obtained. Cornell Hospitality Quarterly, 54(3), 274-283. https://doi.org/10.1177\%2F1938965513481498

Pan, Y., \& Zhang, J. Q. (2011). Born unequal: a study of the helpfulness of user-generated product reviews. Journal of Retailing, 87(4), 598-612. https://doi.org/10.1016/j.jretai.2011.05.002

Park, C., \& Lee, T. M. (2009). Information direction, website reputation and eWOM effect: A moderating role of product type. Journal of Business research, 62(1), 61-67. https://doi.org/10.1016/j.jbusres.2007.11.017

Park, D. H., \& Kim, S. (2008). The effects of consumer knowledge on message processing of electronic word-of-mouth via online consumer reviews. Electronic Commerce Research and Applications, 7(4), 399-410. https://doi.org/10.1016/j.elerap.2007.12.001

Richins, M. L. (1983). Negative word-of-mouth by dissatisfied consumers: A pilot study. The Journal of Marketing, 68-78. https://doi.org/10.2307/3203428

Sen, S., \& Lerman, D. (2007). Why are you telling me this? An examination into negative consumer reviews on the Web. Journal of Interactive Marketing, 21(4), 76-94. https://doi.org/10.1002/dir.20090

Senecal, S., \& Nantel, J. (2004). The influence of online product recommendations on consumers' online choices. Journal of Retailing, 80(2), 159-169. https://doi.org/10.1016/j.jretai.2004.04.001

Sheehan, K. B. (1999). An investigation of gender differences in on-line privacy concerns and resultant behaviors. Journal of Interactive https://doi.org/10.1002/(SICI)1520-6653(199923)13:4\%3C24::AID-DIR3\%3E3.0.CO;2-O

Shim, S., \& Drake, M. F. (1990). Consumer intention to utilize electronic shopping: The Fishbein behavioral intention model. Journal of Direct Marketing, 4(3), 22-33. https://doi.org/10.1002/dir.4000040305

Shin, D., Song, J. H., \& Biswas, A. (2014). Electronic word-of-mouth (eWOM) generation in new media platforms: The role of regulatory focus and collective dissonance. Marketing Letters, 25(2), 153-165. https://doi.org/10.1007/s11002-013-9248-Z

Skowronski, J. J., \& Carlston, D. E. (1989). Negativity and extremity biases in impression formation: A review $\begin{array}{lllll}\text { of } & \text { Psychological } & \text { Bulletin, } & 131 .\end{array}$ http://psycnet.apa.org/doi/10.1037/0033-2909.105.1.131

Swaminathan, V., Page, K. L., \& Gürhan-Canli, Z. (2007). "My" brand or "our" brand: The effects of brand relationship dimensions and self-construal on brand evaluations. Journal of Consumer Research, 34(2), 248-259. https://doi.org/10.1086/518539

Trusov, M., Bucklin, R. E., \& Pauwels, K. (2009). Effects of word-of-mouth versus traditional marketing: findings from an internet social networking site. Journal of Marketing, 73(5), 90-102. https://doi.org/10.1509/jmkg.73.5.90

Tuan Pham, M., \& Chang, H. H. (2010). Regulatory focus, regulatory fit, and the search and consideration of choice alternatives. Journal of Consumer Research, 37(4), 626-640. https://doi.org/10.1086/655668

Tversky, A. (1994). Contingent preferences: LA and tradeoff contrast in decision making. Japanese Psychological Research, 36, 3-9.

Wang, J., \& Lee, A. Y. (2006). The role of regulatory focus in preference construction. Journal of Marketing Research, 43(1), 28-38. https://doi.org/10.1509/jmkr.43.1.28

Wang, X., Yu, C., \& Wei, Y. (2012). Social media peer communication and impacts on purchase intentions: A consumer socialization framework. Journal of Interactive Marketing, 26(4), 198-208. https://doi.org/10.1016/j.intmar.2011.11.004

Wu, P. C., \& Wang, Y. C. (2011). The influences of electronic word-of-mouth message appeal and message source credibility on brand attitude. Asia Pacific Journal of Marketing and Logistics, 23(4), 448-472. https://doi.org/10.1108/13555851111165020 
Xu, C., Wang, W., Chen, J., Wang, W., Yang, C., \& Li, Z. (2010). Analyzing travelers' intention to accept travel information: Structural equation modeling. Transportation Research Record, (2156), 93-100. https://doi.org/10.3141/2156-11

Zaichkowsky, J. L. (1985). Measuring the involvement construct. Journal of Consumer Research, 12(3), 341-352. https://doi.org/10.1086/208520

Zhang, J. Q., Craciun, G., \& Shin, D. (2010). When does electronic word-of-mouth matter? A study of consumer product reviews. Journal of Business Research, 63(12), 1336-1341. https://doi.org/10.1016/j.jbusres.2009.12.011

Zhang, W., \& Watts, S. A. (2008). Capitalizing on content: Information adoption in two online communities. Journal of the Association for Information Systems, 9(2), 73-94.

\section{Appendix A}

Table A. Exemplar of Product Reviews Used in this Study

\begin{tabular}{|c|c|}
\hline Message type & Review Statements \\
\hline Gain & $\begin{array}{l}\text { The foaming and texture are so good. I think it is suitable for the electric toothbrush that I have been using recently } \\
\text { because it produces less bubbles. I was very satisfied. } \\
\text { The foaming of the toothpaste is just perfect. I use it with an electric toothbrush, and the touch feels so good. My } \\
\text { husband was using a different one before, but now, he is using this toothpaste. } \\
\text { When I am using this, I feel so good. It makes me refreshing. I would like to use it again. } \\
\text { I am going to use up this product soon, and the texture is so good. It is so fresh and smooth. I will repeat to buy it. } \\
\text { The texture is really good. It is easy to use because this toothpaste produce less bubbles. I am going to buy it again. }\end{array}$ \\
\hline Non-gain & $\begin{array}{l}\text { Well... as it was developed for hospital use, I expected this product was better than other ones, but I did not feel so. } \\
\text { It didn't meet my expectation. It was harder to make bubbles than other products. I doubt that whether it is good or } \\
\text { bad for my teeth. } \\
\text { Firstly, the dirt wasn't removed well. The stains did not fall, I am going to look for other things. } \\
\text { Is it really effective? I have brushed my teeth every day, and I used this many times, but I always got a cavity, even } \\
\text { though I spent quite a lot of time for brushing my teeth. } \\
\text { Compared to other products, I can say neither it is better nor worse. I think I would not buy it again. }\end{array}$ \\
\hline Non-loss & $\begin{array}{l}\text { This product is hypo-allergenic product. This toothpaste doesn't make my teeth tingle. Also, since I started to use this, } \\
\text { I feel much better when I brush my teeth. } \\
\text { The price is so reasonable. I think this product cheaper than other products. There was no outstanding weakness for } \\
\text { this product. } \\
\text { There were no weird flavors. Also, it doesn't have burning tastes. I love it. } \\
\text { It has mild mint flavor, but there were no burning tastes. I found my children also like this product. } \\
\text { At first, this product has no burning tastes. And its flavor is so soft and mild, I could brush my teeth very slowly. }\end{array}$ \\
\hline Loss & $\begin{array}{l}\text { My hypersensitivity became worse. It is not a good product. I doubt whether it is really hypoallergenic. } \\
\text { Well... I don't think this toothpaste is a good product because it causes bad breath. } \\
\text { This is obviously not good. I changed to other toothpastes because when I used this product, my teeth were bleeding. } \\
\text { I heard that fluorine toothpaste is good to prevent cavities, however, since I use this product, my teeth was getting } \\
\text { yellow. I stopped use this product immediately. } \\
\text { I don't want to put it in my mouth because this product contains two harmful components (propylene glycol, lauryl } \\
\text { sulfate). }\end{array}$ \\
\hline
\end{tabular}

\section{Copyrights}

Copyright for this article is retained by the author(s), with first publication rights granted to the journal.

This is an open-access article distributed under the terms and conditions of the Creative Commons Attribution license (http://creativecommons.org/licenses/by/4.0/). 